\title{
Research on the Development and Innovation of Comparative Literature in the Context of Globalization and Multimedia Environment
}

\author{
Xiaomei Han \\ School of Foreign Languages \\ Qinghai Nationalities University \\ Xining, China 810007
}

\begin{abstract}
The development of network and multimedia environment has promoted the spread of literature, and the application of data analysis has also become an important scientific statistical method. The present study of world literature has surpassed the traditional research content and research method, and pays attention to the practice form of world literature in the era of globalization and the new path of world literature research. The context of globalization has further strengthened the relationship between world literature and comparative literature. The renewal of the concept of world literature and the expansion of the research paradigm reflect the consciousness of comparative literature and the methods of research. The research results reflect the nature of comparative literature and present a trend of comparative literature. The literary consciousness and poetics consciousness embodied in the new progress of world literature are of great edification significance to the deepening and development of comparative literature.
\end{abstract}

Keywords-multimedia; information technology; comparative literature; innovation mode

\section{INTRODUCTION}

International comparative literature has been discussing world literature for more than 10 years. Chinese scholars are also involved. Over the past 10 years, a large number of new papers have been published, and books of creative and pioneering significance have been published, such as Damroch's "what is world literature", Pascale Casanova's "world republic of literature", Franco Monti's "graph, map, tree: abstract pattern of literary history". Chinese comparative literature also provides a special column of "world literature and Comparative Literature", publishing domestic scholars' views and translating relevant articles from foreign scholars, such as Damm Rosh's "national context, world literature", "conjecture of world literature" by John, and the construction of comparative literature and world literature: Construction of comparative literature and world literature. The constructive interdisciplinary relationship has formed a dialogue between Chinese and foreign comparative literature scholars. The discussion of world literature by Chinese and foreign scholars mainly focuses on the following topics: the contemporary interpretation of the concept of Gerd's "world literature", the development and evolution of world literature concepts in different countries, the research paradigm of world literature, the practice form of world literature, the relationship between world literature and comparative literature, and world literature and translation. The discussion of world literature is not only a new understanding of world literature in the age of globalization, but also a reconsideration of the relationship between world literature and comparative literature. The discussion of world literature has formed a set of discourse of contemporary world literature. The renewal of the concept of world literature and the expansion of the research paradigm reflect the consciousness of comparative literature and the methods of research. The research results reflect the nature of comparative literature, and the research of world literature presents a tendency of comparative literature. The new progress in the study of world literature embodies the consciousness of literary noumenon and the question of comparative poetics, which is of great enlightening significance to the deepening and development of comparative literature.

\section{BASIC CONCEPTS AND BASIC FEATURES OF NEW MEDIA}

\section{A. New Media}

The development of new media in the new period is rapid and varied. The impact on the development of radio and television is mainly reflected in the following four aspects: first, the development and application of network video seriously impact on the development of radio and television. Compared with traditional radio and television, network video is rich in content, meets the requirements of various services for users, and network video has high quality image and sound quality. Therefore, it has a serious impact on traditional radio and television. Second, the new media of radio and TV in the new era widely used digital technology, which changed the way of TV's existence. With the wide use of digital technology, the compression and transmission of radio and TV signals has been realized, which enlarges the carrying capacity of channel broadband. Therefore, the development and application of the new media of radio and 
television changes the mode of production of TV channels. In order to adapt to this change, it is necessary to make appropriate adjustments to video channels and establish a special video website. Third, the diversity of new media influences the form of programs in the new era. The main purpose of the traditional TV program is to disseminate information and provide entertainment services for people. However, the new media in the new period has the functions of culture, education, information and communication in addition to the functions of traditional radio and television. In order to adapt to these functions of the new media, it is necessary to make appropriate adjustments to the form of TV programs. Fourth, the development and application of new media in the new era broadened the profit channel of radio and television. The traditional broadcast and television is mainly through the program ratings to gain profit. The application of the new media can gain profit in addition to the application program ratings, and can also gain profit through the way of content sales, service charge, and government subsidy and so on.

\section{B. New Media Development}

In the current situation of rapid development of new media, it is the best way for the development of radio and television, and as mentioned above, some radio and television have been tried and achieved results. However, the integration between the old and the new is not an instant, and the great differences between the two and the operator's haste will lead to a variety of problems. The most serious problem is that radio and television practitioners are not deep enough to understand the integration with the new media, so the integration of the new media is in the form, and radio and television have not yet broken through the traditional barriers. This is a very common situation in some county and City radio and television stations. Practitioners lack understanding of the concept of new media and the essential difference between the traditional radio and television and the new media. It is believed that the portal and the WeChat public are the integration of radio and television with the new media. But they often copy the contents of radio and TV programs without any reading value, let alone high click rate.

\section{NEW PARADIGM FOR THE STUDY OF WORLD LITERATURE}

The international academic community's exploration of world literature is not only a new understanding of world literature in the age of globalization, but also a dialogue between world literature and comparative literature. There are many reasons for the rise of world literature discussion, which is closely related to comparative literature. The comparative literature of China, India, Brazil and other developing countries has made great progress, which has prompted the literature circle of European and American literature to expand the field of view, and the new thinking of international comparative literature has promoted the renewal of the world literature concept. In 1993, Bourne put forward two suggestions on the new trend of comparative literature in the comparative literature of the times of Multicultural Age. One of them is that comparative literature should abandon the European centralism and advocate multiculturalism and expand the visual field of comparative literature to the East and the West. With the deconstruction of traditional European centralism, "world literature has a real sense of the global dimension, no longer simply reflects the western traditional culture mode." This is also reflected in the selection of works in the world literature collection. The editor began to pay attention to the literary works of the countries outside Europe and the United States, though the proportion was relatively small, but it broke the situation that European and American literature dominated this kind of literature.

The study of world literature from a whole point of view, whether it is an exposition of the universal poetics or the interaction between literature, belongs to the content of comparative literature, for example, from the viewpoint of "the world literature is not the object, but the problem", Franco mrety studies the problems of the morphology of the world novel itself. The overall outlook and comparative consciousness of world literature in comparative literature are of great significance to the compilation of world literature history and the compilation of world literature collections. From the perspective of comparative literature, world literature is no longer a collection of literary works in the sense of isolation and freedom from each other, but a literary community with some common traits and inherent or external connections. As Yue Dai Yun said, comparative literature "contributes to the cohesion and variation of world literature. There is not a comparative literature of epistemology (interactive cognition) and methodology (mutual recognition, mutual evidence and complementarity). World literature is difficult to develop, and even can only be an accumulation of meaningless materials or a plate of sand." The establishment of the world literature history and the criteria for the selection of world literature collections need the methods and achievements of comparative literature.

The translation of literary works, cross-cultural communication, the internal and external links between literature, and the exploration of common poetics has always been the research topics of comparative literature. At present, many issues in the study of world literature are originally in the category of comparative literature, and the methods of world literature study of Damm Roche and Moretti and other scholars are also the methods of comparative literature. Therefore, the research perspectives and questions of the new world literature, such as the question of comparative reading and the relationship between world literature and translation, are also the subject of comparative literature.

Damroch said: "even in the country already has a classic status works, when it spreads abroad, it will also get a new dimension. It is different to read Shakespeare's works with the works of Alfonso Fochler J and Bly Hitt, and to read the works of his works and his compatriots like Marlowe and Jonson. "The cross cultural reading problem raised here is interlinked with Susan basnnet's view. Basnet, aiming at the crisis of comparative literature, put forward in the literature review of comparative literature in twenty-first Century that the future development of comparative literature is to abandon any prescriptive methods that restrict the research 
objects, to hold the most open literary view and to recognize the interconnections that the literature will inevitably bring. The specific way is "to highlight the role of readers, to compare in the process of reading, rather than to pre restrict, only to select specific text to read." It is suggested that "do not make meaningless arguments for terms and definitions, study the text more effectively, describe the history of cross culture, cross space and time, and the history of reading".

Damroch emphasized the key role of translation in the construction of world literature, and believed that world literature is the "gains in translation" literature. He pointed out: "all works, once translated, are no longer the unique products of their original culture, but are turned into" original works". "Once a work enters world literature, it gets a new life. To understand this new life, it is necessary to carefully examine how the work is in the translation and the new cultural context. In fact, the western contemporary translation theory of target-culture-oriented and the translation of Chinese contemporary comparative literature have already expressed similar views, that is, to pay attention to the entry of literary works into a new cultural context, from the choice of translation, the process of translation, the strategy of translation to the circulation of the translation, and the evaluation of the works.

\section{THE ENLIGHTENMENT OF COMPARATIVE LITERATURE}

The discussion of world literature has further closely related the relationship between world literature and comparative literature, and the research of world literature is becoming more and more literary. World literature is the object of comparative literature. The world literature, as the object of comparative literature, is not from the textual level, but to the relationship between literary and literary nature in the world literature community. The meaning of traditional world literature research is a collection of studies on different national literature or author's works. It is necessary for scholars from different countries to complete the research. The research on world literature of Damm Roche and holti surpassed the research level of the specific text, emphasizing the integrity, cross culture and common poetics of the study, which raised the study of world literature to the level of comparative literature. Such a study of world literature is indistinguishable from comparative literature, or even a comparative literature study.

Most of the participants in the world literature are comparative literary scholars. They consciously use comparative literature methods to study world literature. Their research results have the nature of comparative literature. This is a natural matter. This paper analyzes the comparative literature factors in the new world literature research; one is to continue to explore the relationship between world literature and comparative literature. Two, it is to reflect on and reflect on the present situation of contemporary comparative literature, and to think about the significance of the new progress in the study of world literature on the deepening of comparative literature research.

Since 1970s, comparative literature has been more and keener on theoretical research and cultural research, and divorced from literary ontology. Taking the United States as an example, the Department of comparative literature in the United States is known as "the hotbed of theory". "Some of the best graduate schools, and their comparative literature, focus on theories rather than literature, rather than methods." Even if it involves literature, it will only regard literature as an argument material for presupposition theory, or a test for various theories. "Theoretical craze" not only led to the anomie of comparative literature, but also made the subject consciousness lose. Interdisciplinary research should be a new field of comparative literature, but the subsequent development of interdisciplinary research gradually deviated from its original intention, and finally evolved into a pan subject study, losing its literary nature and thus lost its comparative literary nature. Remarque, the initiator of interdisciplinary studies, deeply regrets the generalization of interdisciplinary research: "the interdisciplinary momentum has reversed the comparative literature which is the core of cross - language and cross - language." The new paradigm of world literature research has strong interdisciplinary characteristics. Moretti and Casanova used the theory of evolution and world system theory to explain the form and development of world literature. They also used interdisciplinary approaches, but they focused on literature. Comparative literature is keen to open up its territory, but has no intention of running its own territory that should be carefully cultivated.

\section{CONCLUSION}

The emergence of comparative literature has benefited from the formation of the concept of world literature, which has become the theoretical basis for the establishment of comparative literature, and the development of comparative literature provides a theoretical perspective and research method for the development and deepening of the study of world literature. The new development of the concept and research paradigm of world literature has also given profound enlightenment to the comparative literature in a state of confusion. The new paradigm of world literature research put forward by the world literature discussion focuses on literature, which is a backwash to the heat of theoretical and cultural research in the field of comparative literature for the past 20 years. The consciousness of literary noumenon and the problem of poetics embodied in the new progress of world literature research are both enlightening and reminding to Comparative Literature: the research field of vision can be broad, the research object can be diverse and the research method can be pluralistic, but it can not obscure its basic target, lost the direction of development and detracts itself.

\section{REFERENCES}

[1] Datta, S.K., Bonnet, C. and Haerri, J., 2017, June. Extending DataTweet IoT Architecture for Virtual IoT Devices. In 10th IEEE International Conference on Internet of Things (iThings-2017), pp. 16.

[2] Jeuring, J. H. G. (2015). "Discursive contradictions in regional tourism marketing strategies: the case of fryslân, the Netherlands". Journal of Destination Marketing \& Management, 5(2), 65-75. 
[3] Polo Peña, A. I., Chica Olmo, J., Frías Jamilena, D. M., \& Rodríguez Molina, M. Á. (2015). "Market orientation adoption among rural tourism enterprises: the effect of the location and characteristics of the firm". International Journal of Tourism Research, 17(1), 54-65.

[4] Huang, W., Wang, H., Zhang, Y. and Zhang, S., 2017. A novel cluster computing technique based on signal clustering and analytic hierarchy model using hadoop. Cluster Computing, pp.1-8.

[5] Jackson, D., Barrett, J.K., Rice, S., White, I.R. and Higgins, J., 2014 A design-by-treatment interaction model for network meta-analysis with random inconsistency effects. Statistics in medicine, 33(21), pp.3639-3654.

[6] Li, X., Ma, K., George, S., Sampson, J. and Narayanan, V., 2016 September. Enabling Internet-of-Things: Opportunities brought by emerging devices, circuits, and architectures. In Very Large Scale Integration (VLSI-SoC), 2016 IFIP/IEEE International Conference. pp. 1-6.

[7] Markus, A., Kecskemeti, G. and Kertesz, A., 2017, March. Flexible Representation of IoT Sensors for Cloud Simulators. In Parallel, Distributed and Network-based Processing (PDP), 2017 25th Euromicro International Conference, pp. 199-203.

[8] Song, Y.E., Liu, Y., Fang, S. and Zhang, S., 2015, August. Research on applications of the internet of things in the smart grid. In Intelligent Human-Machine Systems and Cybernetics (IHMSC), 2015 7th International Conference, Vol. 2, pp. 178-181.

[9] Tao, F., Zuo, Y., Da Xu, L. and Zhang, L., 2014. IoT-based intelligent perception and access of manufacturing resource toward cloud manufacturing. IEEE Transactions on Industrial Informatics, 10(2), pp.1547-1557.

[10] Tila, F. and Kim, D.H., 2015. Semantic IoT System for Indoor Environment Control-A Sparql and SQL based hybrid model. Advanced Science and Technology Letters, 120, pp.678-683.

[11] Zhang, Y., Wang, H. and Xie, Y., 2017. An intelligent hybrid model for power flow optimization in the cloud-IOT electrical distribution network. Cluster Computing, pp.1-10. 